\title{
Luteolin Modulates SERCA2a Leading to Attenuation of Myocardial Ischemia/ Reperfusion Injury via Sumoylation at Lysine 585 in Mice
}

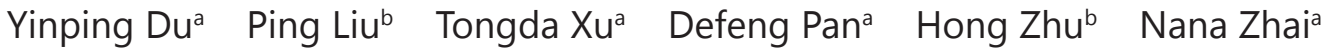 \\ Yanbin Zhang ${ }^{b}$ Dongye Li ${ }^{a, b}$ \\ anstitute of Cardiovascular Disease Research, Xuzhou Medical University, Xuzhou, Jiangsu, bDepartment \\ of Cardiology, The Affiliated Hospital of Xuzhou Medical University, Xuzhou, Jiangsu, PR China
}

\section{Key Words}

Serca2a • Ischemia/reperfusion • SUMOylation • Luteolin

\begin{abstract}
Background/Aims: The myocardial sarcoplasmic reticulum calcium ATPase (SERCA2a) is a pivotal pump responsible for calcium cycling in cardiomyocytes. The present study investigated the effect of luteolin (Lut) on restoring SERCA2a protein level and stability reduced by myocardial ischemia/reperfusion (I/R) injury. We verified a hypothesis that Lut protected against myocardial I/R injury by regulating SERCA2a SUMOylation. Methods: The hemodynamic data, myocardial infarct size of intact hearts, apoptotic analysis, mitochondrial membrane potential $(\Delta \Psi \mathrm{m})$, the level of SERCA2a SUMOylation, and the activity and expression of SERCA2a were examined in vivo and in vitro to clarify the cardioprotective effects of Lut after SUMO1 was knocked down or over-expressed. The putative SUMO conjugation sites in mouse SERCA2a were investigated as the possible regulatory mechanism of Lut. Results: Initially, we found that Lut reversed the SUMOylation and stability of SERCA2a as well as the expression of SUMO1, which were reduced by I/R injury in vitro. Furthermore, Lut increased the expression and activity of SERCA2a partly through SUMO1, thus improving $\Delta \Psi_{\mathrm{m}}$ and reducing apoptotic cells in vitro and promoting the recovery of heart function and reducing infarct size in vivo. We also demonstrated that SUMO acceptor sites in mouse SERCA2a involving lysine 585, 480 and 571. Among the three acceptor sites, Lut enhanced SERCA2a stability via lysine 585. Conclusions: Our results suggest that Lut regulates SERCA2a through SUMOylation at lysine 585 to attenuate myocardial I/R injury.

Y. Du, P. Liu and T. Xu contributed equally to this work.

Dongye Li

and Tongda Xu

KARGER
Institute of Cardiovascular Disease Research, Xuzhou Medical University, 84 West

Huaihai Road, 221002. Department of Cardiology, The Affiliated Hospital of

Xuzhou Medical University, 221006, Xuzhou, Jiangsu (PR China)

Tel. +86-516-85582763, E-Mail dongyeli@medmail.com.cn 


\section{Cellular Physiology Cell Physiol Biochem 2018;45:883-898

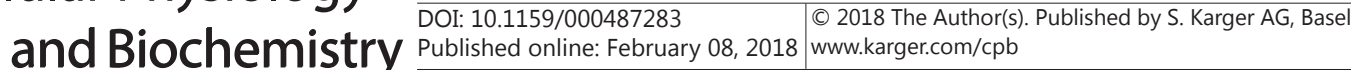 \\ Du et al.: Lut Attenuates Myocardial I/R Injury via SERCA2a}

\section{Introduction}

In acute myocardial infarction, reperfusion is an efficient method of salvaging the ischemic myocardium, and includes thrombolysis, percutaneous coronary intervention and coronary artery bypass graft surgery. However, reperfusion itself can induce further irreversible cell injury and death. Ischemia/reperfusion (I/R) injury triggers a series of adverse events, such as reperfusion arrhythmia, myocardial systolic/diastolic dysfunction, no reflow and even sudden death [1]. Therefore, it is vital to investigate the pathogenesis of I/R injury and search for effective new drugs to alleviate or avoid myocardial I/R injury. The cellular and molecular biological mechanisms of myocardial I/R injury are complicated and likely involve oxidative stress, calcium overload, cell inflammation, and mitochondrial permeability transition pore opening which initiates apoptosis and necrosis [2, 3]. Of these, calcium overload is probably the main cause of I/R injury $[4,5]$.

Intracellular calcium concentration is regulated by a group of ion channels, transporters and pumps in a highly coordinated manner. Cardiac sarcoplasmic reticulum calcium ATPase (SERCA2a) plays an important role in myocardial excitation-contraction coupling. As a calcium pump, SERCA2a is responsible for taking up calcium from the cytosol into the sarcoplasmic reticulum (SR). The activity of SERCA2a is dynamically regulated by phospholamban phosphorylation, resulting in enhanced calcium transport into the SR, thereby preparing the next contraction cycle [6]. The SERCA2a promoter is involved in I/R injury and reduced SERCA2a activity is extraordinarily harmful for heart systolic/diastolic function [7-9]. As SERCA2a has an essential effect on intracellular calcium homeostasis, the potential molecular mechanism of SERCA2a in myocardial I/R injury deserves to be explored. SUMO, a small ubiquitin-like modifier, belongs to a family of ubiquitin-like proteins. SUMO isoforms may have overlapping targets but exhibit preferred substrate specificities. For instance, RanGAP1 and Nkx2.5 are favored by SUMO1 [10]. SUMOylation is a reversible post-translational modification where SUMO is covalently conjugated to the lysine residues of a target by enzymatic reactions [11]. SUMOylation has emerged as a crucial post-translational regulatory mechanism of target proteins in many cellular processes, including protein stability, transcriptional regulation, and response to stress $[10,12]$. In the heart, SUMOylation has a crucial impact on normal cardiac development and function [13], as well as adaptation of the heart to pathological stress [14]. It has been reported that enhanced SERCA2a SUMOylation can improve cardiac function via SUMO1 gene transfer in swine with heart failure [15]. The small molecule, N106 (N-(4-methoxybenzo [d]thiazol-2yl)-5-(4-methoxyphenyl)-1, 3,4-oxadiazol-2-amine has been shown to enhance SERCA2a SUMOylation, resulting in enhanced contractility of the failing heart [16]. However, very few studies have investigated the role of SERCA2a SUMOylation in myocardial I/R injury.

Luteolin (Lut) is a natural soluble flavone present in many plants. Our previous studies have demonstrated that Lut can protect the myocardium from I/R injury by down-regulating microRNA-208b-3p [17] and the PI3K/Akt pathway [18]. Moreover, decreased expression and activity of SERCA2a can be partly reversed by Lut $[19,20]$. These studies provide evidence that Lut has a protective effect on heart.

According to previous reported results, Lut has been implicated as a modulator of SERCA2a against myocardial I/R injury. We questioned whether Lut could modulate SERCA2a through SUMOylation in vivo and in vitro. Thereby, we first determined the influence of Lut on the stability and SUMOylation of SERCA2a. Secondly, the relationship between Lut, SUM01 and SERCA2a was evaluated by knockdown and over-expression of SUM01. Thirdly, we determined the putative SUMO conjugation sites in mouse SERCA2a, and detected the interaction between the cardio-protective effect of Lut and these conjugation sites. Thus, these findings may reveal the potential therapeutic targets of an effective drug for the clinical prevention and treatment of myocardial I/R injury. 


\section{Cellular Physiology Cell Physiol Biochem 2018;45:883-898 \begin{tabular}{ll|l} 
DOI: 10.1159/000487283 & $\begin{array}{l}\text { O } 2018 \text { The Author(s). Published by S. Karger AG, Basel } \\
\text { www.karger.com/cpb }\end{array}$
\end{tabular} \\ Du et al.: Lut Attenuates Myocardial I/R Injury via SERCA2a}

\section{Materials and Methods}

Animal care and reagents

All the animal experiments were approved by the Animal Ethics Committee of Xuzhou Medical University, Xuzhou, China, and conformed to the NIH guidelines (Guide for the care and use of laboratory animals). Male C57BL/6J mice (Xuzhou Medical University) weighing 20-25 g were used in the study. Lut (Fluka; purity > 98\%; Sigma-Aldrich, Seelze, Germany) was dissolved in dimethyl sulfoxide (DMSO) and diluted with culture medium to a final concentration of $0.01 \%$, which had no side-effects on the heart [21].

\section{$H L-1$ cell culture}

HL-1 cells, derived from mouse atrial hyperplastic cardiac muscle cells, were cultured in Claycomb Medium (Sigma-Aldrich, Saint Louis, MO, USA) supplemented with 10\% fetal bovine serum, $100 \mu \mathrm{g} / \mathrm{ml}$ penicillin/streptomycin, $2 \mathrm{mM}$ L-glutamine, and $0.1 \mathrm{mM}$ norepinephrine. Cells were plated in tissue culture flasks coated an hour previously with gelatin $(0.02 \% \mathrm{w} / \mathrm{v})$ and fibronectin $(0.5 \% \mathrm{v} / \mathrm{v})$ [22].

\section{Simulated I/R model using $H L-1$ cells}

Cells in the different groups were treated as follows: Control (Con) group, cells were cultured in Claycomb Medium at normoxia $\left(21 \% \mathrm{O}_{2}\right)$ and $37^{\circ} \mathrm{C}$; Simulated I/R (SI/R) group, cells were grown in Claycomb Medium at normoxia $\left(21 \% \mathrm{O}_{2}\right)$ and $37^{\circ} \mathrm{C}$, and then subjected to 2 h hypoxia $\left(1 \% \mathrm{O}_{2}\right)$ followed by 2 h normoxia $\left(21 \% \mathrm{O}_{2}\right)[23,24]$; Lut pretreatment (Lut+SI/R) group, cells were pretreated with Lut $(8 \mu \mathrm{M})$ for $12 \mathrm{~h}$ followed by SI/R.

\section{$I / R$ injury in mouse myocardium in vivo}

Mice were anesthetized with pentobarbital sodium $(50 \mathrm{mg} / \mathrm{kg})$ intraperitoneally. A left thoracotomy was performed followed by opening of the pericardium to expose the heart. An 8-0 silk suture was passed underneath the left coronary artery (LAD, $2 \mathrm{~mm}$ inferior to the left atrial appendage) [25]. Occlusion was confirmed when left ventricular color changed from red to pallor and ST segment elevation was seen on ECG. Each group was subjected to $30 \mathrm{~min}$ of ischemia. The knot was then released to start reperfusion for $24 \mathrm{~h}$. Reperfusion was identified by the recovery of left ventricular color and the variation in ECG. The Sham group underwent the same procedure with the exception of LAD ligation.

\section{Drug administration}

C57BL/6J mice were randomly divided into the sham operation group (Sham), I/R group, I/R+DMSO group, Lut5 $\mu \mathrm{g} / \mathrm{kg}+\mathrm{I} / \mathrm{R}$ group, Lut10 $\mu \mathrm{g} / \mathrm{kg}+\mathrm{I} / \mathrm{R}$ group, Lut15 $\mu \mathrm{g} / \mathrm{kg}+\mathrm{I} / \mathrm{R}$ group, Lut20 $\mu \mathrm{g} / \mathrm{kg}+\mathrm{I} / \mathrm{R}$ group and Lut25 $\mu \mathrm{g} / \mathrm{kg}+\mathrm{I} / \mathrm{R}$ group. Before I/R, Lut was administered by tail vein injection once a day for 3 days [26]. The Sham and I/R group received $25 \mu \mathrm{g} / \mathrm{kg}$ of normal saline for three days. The I/R+DMSO group received $25 \mu \mathrm{g} / \mathrm{kg}$ of DMSO for three days.

\section{MTT assay of cardiac tissue}

An MTT assay was performed to test cell viability in cardiac tissue. Briefly, following 30 min ischemia and $24 \mathrm{~h}$ reperfusion, cardiac tissue was weighed and frozen. The hearts were then cut transversely into 2-mm-thick slices, which were incubated with MTT (3 mM) for $30 \mathrm{~min}$ at $37^{\circ} \mathrm{C}$ and homogenized in DMSO (40 ml/g). The supernatant was collected following centrifugation at $1000 \times g$ for $10 \mathrm{~min}$. The optical density at $550 \mathrm{~nm}$ was read with a microplate reader (Bio-Rad 550, Hercules, CA, USA).

Measurement of plasma lactate dehydrogenase ( $L D H)$ level

Following completion of the I/R model, carotid blood was collected from each group. The blood was centrifuged at $1000 \times g$ for $10 \mathrm{~min}$, and the concentration of plasma LDH was determined using an LDH activity assay kit (BioVison, Milpitas, CA, USA).

\section{siRNA and plasmid constructions}

The siRNA of SUM01 (si-SUM01) was designed and synthesized by GenePharma (Shanghai, China), and the sequence of si-SUMO1 was as follows: sense, 5'-CUGAGGACUUAGGCGAUAATT-3'; antisense, 3'-UUAUCGCCUAAGUCCUCAGTT-5'. 


\section{Cellular Physiology Cell Physiol Biochem 2018;45:883-898 \begin{tabular}{l|l|l|l|l} 
DOI: 10.1159/000487283 2018 The Author(s). Published by S. Karger AG, Basel & $\begin{array}{l}\text { Co } \\
\text { www.karger.com/cpb }\end{array}$
\end{tabular} \\ Du et al.: Lut Attenuates Myocardial I/R Injury via SERCA2a}

The over-expressed SUM01 plasmid (EGFP-SUMO1) was purchased from GenePharma (Shanghai), and the vector was the pEX-2 plasmid containing enhanced green fluorescent protein (EGFP). Empty vector was used as the control plasmid.

Plasmids encoding wild type (WT) or SUMOylation site mutants of SERCA2a were purchased from Hanbio (Shanghai, China) with mutations at the lysine residue (K) to arginine (R). Point mutantion derivatives of SERCA2a (K585R, K480R, K571R, K585R/K480R, K585R/K571R, K480R/571R and K585R/ K480R/571R) and WT were constructed in pIRES-EGFP plasmids. All transfections were performed using Lipofectamine 2000 according to the manufacturer's instructions (Invitrogen, Carlsbad, CA, USA).

\section{Transient transfection with AV-sh-SUMO1}

Replication-deficient adenoviral vectors encoding SUM01 interfering sequence with green fluorescent protein (AV-sh-SUM01) or green fluorescent protein alone (AV-sh-NULL) were generated by JiMan (Shanghai, China). The sequence of AV-sh-SUMO1 was as follows: sense, 5'-CUGAGGACUUAGGCGAUAATT-3'; antisense, 3 '-UUAUCGCCUAAGUCCUCAGTT-5'. AV-sh-SUMO1 or AV-sh-NULL $\left(1 \times 10^{10}\right.$ plaque-forming units $)$ in a total volume of $10 \mu \mathrm{l}$ was injected into the free wall of the left ventricle using a 30-gauge needle. The injection site was distributed from the apex upward and three adjacent sites on the left ventricular free wall [25]. Gene transfer was performed 3 days before I/R injury. The efficiency of transfection was determined by observation of myocardial green fluorescence and the detection of SUM01 expression.

\section{Assessment of area at risk and infarct size}

Myocardial infarct size was determined by Evans Blue/triphenyltetrazolium chloride (TTC) staining. At the end of reperfusion, the animals were re-anesthetized with pentobarbital sodium $(50 \mathrm{mg} / \mathrm{kg})$ intraperitoneally and intubated. The chest was opened again, and the LAD was re-ligated at the same position. Evans blue dye ( $0.2 \mathrm{ml}$ of a $2.0 \%$ solution) was injected into the left ventricular cavity followed by a cardioplegic solution ( $10 \%$ potassium chloride) to ensure the heart stopped in diastole. The heart was then excised, frozen for $10 \mathrm{~min}$ to harden the tissue, and serially sectioned from the apex to the atrioventricular groove into five slices, approximately $1.5 \mathrm{~mm}$ in thickness. The slices were incubated with $1 \% \mathrm{TTC}$ at $37^{\circ} \mathrm{C}$ for $15 \mathrm{~min}$ in the dark. The samples were then fixed in a 10\% formalin solution for $2 \mathrm{~h}$. Each section was weighed, digitally photographed and analyzed using Image J software (National Institutes of Health, MD, USA). Evans blue-stained areas were defined as non-ischemic areas. The area of myocardium not stained with Evans blue was defined as the area at risk (AAR). TTC and Evans blue-unstained areas were defined as infarcted zones.

\section{Measurement of hemodynamics}

Cardiac function was determined $24 \mathrm{~h}$ after reperfusion by a catheter connected to a pressure transducer. In brief, after the mouse was re-anesthetized with $1 \%$ isoflurane $(\mathrm{v} / \mathrm{v})$, the right carotid artery was isolated and the conductance catheter was inserted which was pre-soaked in $\mathrm{NaCl}\left(0.9 \%, 37^{\circ} \mathrm{C}\right)$ for 30 min. After stabilization, the left ventricular systolic pressure (LVSP), left ventricular end-diastolic pressure (LVEDP), maximal rate of pressure development $(+\mathrm{dP} / \mathrm{dtmax})$ and maximal rate of pressure decrease $(-\mathrm{dP} /$ dtmax) were determined using the BL420s Biological function test system (TaiMeng, Chengdu, China). At the end of experiment, the mice were euthanasia with an overdose of pentobarbital sodium $(150 \mathrm{mg} / \mathrm{kg})$.

\section{Detection of apoptotic cells}

Cell apoptosis was examined by the Annexin V-APC/propidium iodide (PI) dual staining kit (eBioscience, San Diego, CA, USA). The cells were resuspended in $100 \mu \mathrm{l}$ binding buffer and incubated with $5 \mu \mathrm{l}$ Annexin $\mathrm{V}$-APC for $15 \mathrm{~min}$ at room temperature in the dark according to the manufacturer's instructions. Following the addition of $5 \mu \mathrm{l}$ PI, apoptotic cells were evaluated using flow cytometry (Becton Dickinson, San Jose, CA, USA). Annexin $\mathrm{V}^{-} / \mathrm{PI}^{-}$staining indicated surviving cells. Early apoptosis appeared as Annexin $\mathrm{V}^{+} / \mathrm{PI}^{-}$. $\mathrm{PI}^{+}$cells represented apoptotic cells at the terminal stage or necrotic cells.

Measurement of mitochondrial membrane potential $(\Delta \Psi \mathrm{m})$

Alteration of $\Delta \Psi \mathrm{m}$ was measured by the JC-1 Mitochondrial Membrane Potential assay kit (Kaiji Bio, Nanjing, China). Briefly, JC-1 staining solution $(5 \mu \mathrm{g} / \mathrm{ml})$ was added to six-well plates. The cells were subsequently incubated for $20 \mathrm{~min}$ at $37^{\circ} \mathrm{C}$, washed twice with JC-1 staining buffer, and then collected to 


\section{Cellular Physiology Cell Physiol Biochem 2018;45:883-898 \begin{tabular}{l|l|l} 
and Biochemistry Published online: February 08, 2018 & $\begin{array}{l}\text { (c) } 2018 \text { The Author(s). Published by S. Karger AG, Basel } \\
\text { www.karger.com/cpb }\end{array}$ \\
\hline DOI.
\end{tabular} \\ Du et al.: Lut Attenuates Myocardial I/R Injury via SERCA2a}

assess $\Delta \Psi \mathrm{m}$ by flow cytometry (Becton Dickinson). JC- 1 is present as red fluorescence J-aggregates in cells with a high $\Delta \Psi \mathrm{m}$. A green fluorescent monomer is formed in depolarized mitochondria. The changes in $\Delta \Psi \mathrm{m}$ were evaluated by the monomer/aggregate emission ratio.

\section{Quantitative real-time PCR ( $q$ RT-PCR)}

Total RNA was isolated using TRIzol Reagent (Invitrogen). $2 \mu \mathrm{g}$ RNA was reverse transcribed with Transcript First-strand cDNA synthesis SuperMix (TransGen Biotech, Beijing, China). The mRNA level was determined by qRT-PCR using an ABI PRISM7900 system (Applied Biosystems, CA, USA). The results were normalized with $\beta$-actin. The primer sequences were designed by GenePharma (Shanghai, China) as follows: SERCA2a forward, 5'-CGGTGCCTTTGTTGTCTCCA-3', SERCA2a reverse, 5'-ACCTGACTTTCGTCGGCTGTGT-3'; $\beta$-actin forward, 5'-TGAGAGGGAAATCGTGCGTGAC-3', $\beta$-actin reverse, 5'-GCTCGTTGCCAATAGTGATGACC-3'.

\section{Western blot}

Cells and tissues were lysed with $100 \mu \mathrm{l}$ ice-cold RIPA lysis buffer (Beyotime, Shanghai, China) supplemented with $1 \mu \mathrm{l} 100 \mathrm{mM}$ phenylmethanesulfonyl fluoride (Beyotime) for $30 \mathrm{~min}$. The total protein extract was collected following centrifugation at $12,000 \times \mathrm{g}$ for $15 \mathrm{~min}$ at $4^{\circ} \mathrm{C}$. Protein samples were subjected to SDS-polyacrylamide gel electrophoresis followed by transfer onto polyvinylidene fluoride membranes. Non-specific binding was blocked with Tris-buffered saline/Tween-20 for $3 \mathrm{~h}$ at room temperature. The blots were then probed with primary antibodies targeting rabbit anti-SUM01 (1:2000; Santa Cruz Biotechnology, Santa Cruz, CA, USA), mouse anti-SERCA2a (1:5000; Abcam, Cambridge, UK), mouse anti-Bcl-2, mouse antiBax (1:1000; Santa Cruz Biotechnology, Santa Cruz, CA, USA), rabbit anti-caspase-3, rabbit anti-cleavedcaspase-3 (1:1000; Cell Signaling technology, CST, USA) at $4^{\circ} \mathrm{C}$ overnight. The blots were probed again with anti-mouse-HRP and anti-rabbit-HRP secondary antibodies at $37^{\circ} \mathrm{C}$ for $1 \mathrm{~h}$. The immunoreactive bands were visualized using an enhanced Chemiluminescence (ECL, Merck Millipore, Billerica, MA, USA) method. Quantification of the blots was measured with Image J software (National Institutes of Health). Monomeric SUM01 and SUM01 conjugates, such as SUM01-RanGAP showed the same trend [27]. SUM01-RanGAP was used to represent total SUM01.

\section{Measurement of SERCA2 a activity}

SERCA2a activity in heart tissue was determined by an ATPase Assay Kit (Jiancheng, Nanjing, China) according to the manufacturer's instructions. ATP can be resolved by ATPase into ADP and Pi, therefore, in our test the quantity of Pi was detected to reflect the ATPase activity. One unit of ATPase activity was defined as the amount of Pi which was resolved by ATPase per milligram tissue protein per hour, and was expressed as $\mu \mathrm{molPi} / \mathrm{mgprot} /$ hour. Protein concentration was measured using the BCA Assay Kit (Beyotime).

Assessment of SERCA2a stability

Cells were treated with culture media containing $100 \mu \mathrm{g} / \mathrm{ml}$ cycloheximide (Solarbio, Beijing, China) after Lut treatment and transfection with plasmids for $48 \mathrm{~h}$ to inhibit protein synthesis. Protein of cells from each group was extracted on days 0,3 and 5 afer cycloheximide treatment. Western blot analysis was performed to detect the remaining SERCA2a at different time points.

\section{SUMOylation assay}

The cell and tissue lysates were immunoprecipitated using the Catch and Release® Reversible Immunoprecipitation System (Merck Millipore) following the manufacturer's instructions. Extracted proteins $(500 \mu \mathrm{g})$ were incubated with $2 \mu \mathrm{g}$ of SUMO1 primary antibody or normal rabbit IgG on a rotator at $4^{\circ} \mathrm{C}$ overnight. The proteins were eluted by the addition of $70 \mu \mathrm{l}$ of elution buffer and analyzed by western blot.

\section{Statistical analysis}

Data are shown as means \pm standard errors of the mean. Statistical analysis was performed by one-way and two-way ANOVA using GraphPad Prism 5.0 software (GraphPad Software, Inc., CA, USA). P<0.05 was considered statistically significant. 
Fig. 1. Lut upregulates SERCA2a and SUM01 and improves SERCA2a's SUMOylation and stability. (A) SERCA2a protein expression in SI/R process and pretreatment of Lut. (B) SUM01 protein level in subjected to SI/R injury and pretreated with Lut. (C) The effects of Lut on SERCA2a SUMOylation during SI/R. (D) SERCA2a protein stability in each treatment group. (E) Results of plasma LDH level. (F) Myocardial activity by MTT assay detected at $550 \mathrm{~nm}$. Data are presented as mean \pm SEM $(n=3)$. $\Delta \mathrm{P}<0.05, \Delta \Delta \mathrm{P}<0.01, \Delta \Delta \Delta \mathrm{P}<0.001$ versus Con; ${ }^{*} \mathrm{P}<0.05,{ }^{* *} \mathrm{P}<0.01$ versus $\mathrm{SI} / \mathrm{R}$; $\& \& \mathrm{P}<0.01, \& \& \& \mathrm{P}<0.001$ versus Sham; $\# \mathrm{P}<0.05$, \#\#\#P<0.001 versus I/R.

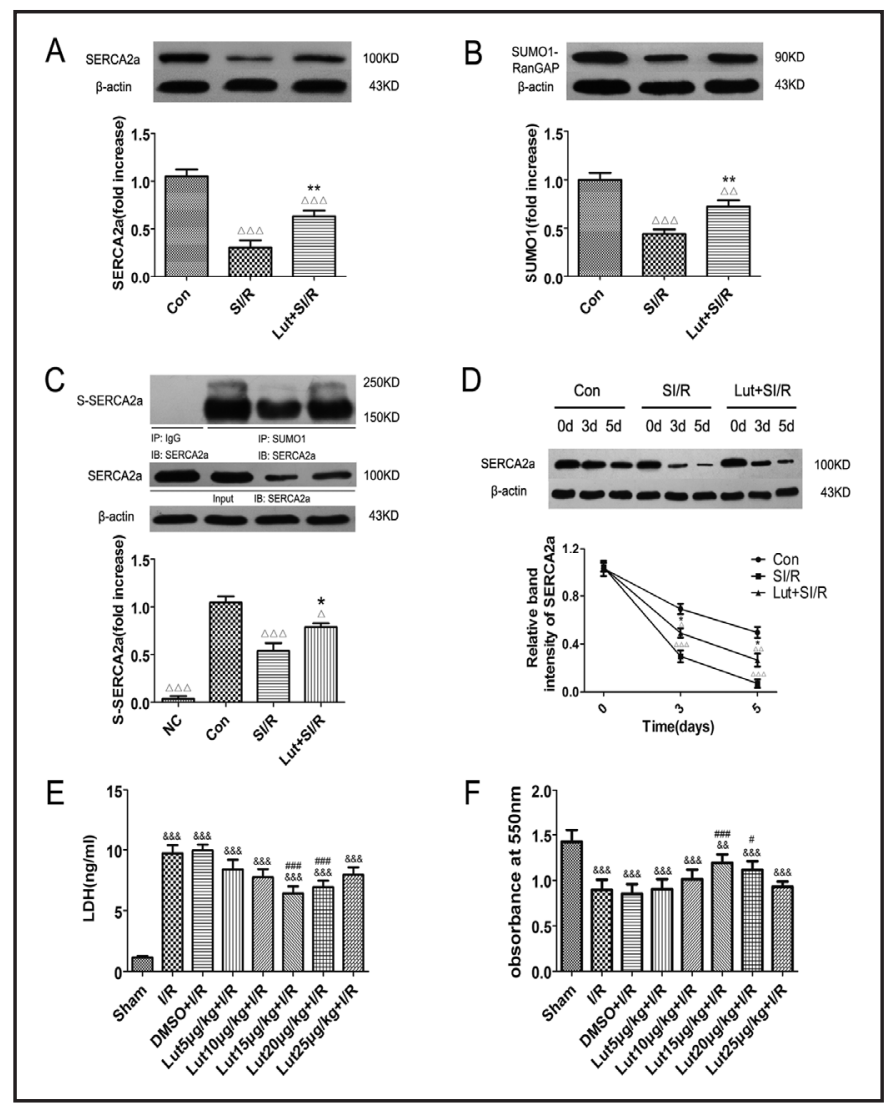

Fig. 2. The filtration and efficiency of AV-sh-SUM01, si-SUM01 and EGFPSUM01. (A) Myocardial green fluorescence was significantly decreased in AV-sh-SUM01-injected hearts compared with AV-sh-NULL-injected animals. (B) SUMO1 protein expression in AV-sh-NULL and AV-sh-SUMO1 injected hearts. (C) The effect of transfection with si-SUM01 on SUM01 protein level in HL-1 cells. (D) SUMO1 mRNA expression significantly decreased in HL-1 cells transfected with si-SUMO1. (E) The protein level of SUM01 was increased after EGFP-SUM01 transfecton in cells. (F) Results of SUM01 mRNA expression in HL-1 cells transfected with EGFP-SUM01. Data are presented as mean \pm SEM $(n=3)$. aaa $\mathrm{P}<0.001$ versus con; bbb $\mathrm{P}<0.001$ versus $\mathrm{AV}$-sh-NULL; $\Delta \Delta \mathrm{P}<0.01, \Delta \Delta \Delta \mathrm{P}<0.001$ versus Con; $* * \mathrm{P}<0.01, \quad * * * \mathrm{P}<0.001$ versus si-con; $\# \# \# \mathrm{P}<0.001$ versus Con; $\& \& \& \mathrm{P}<0.001$ versus EGFP-SUM01.

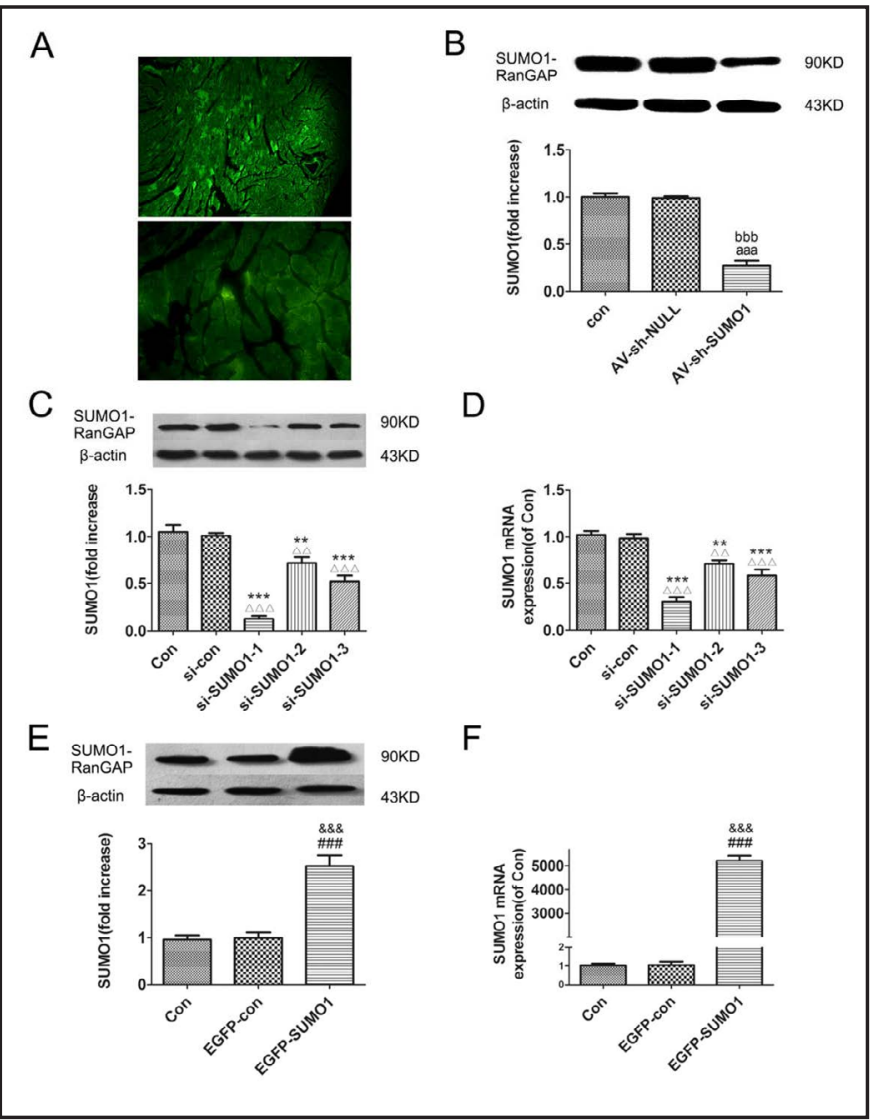


Fig. 3. Expressions of SERCA2a and SUMO1, the level of SERCA2a SUMOylation and SERCA2a activity in each treatment group. (A) The protein level of SERCA2a in vivo with the transfection of AV-sh-SUM01. (B) SUM01 protein expression in vivo. (C) HL-1 cells were pre-treated with siRNA to knockdown SUM01 and plasmids to over-express SUM01. Cells were then stimulated with SI/R following the pretreatment of Lut. SERCA2a protein level was analyzed by Western blot. (D) Analysis of SERCA2a mRNA expression in each group HL-1 cells by qRT-PCR. (E) The expression of SUMOylated SERCA2a in vivo with the transfection of AV-sh-SUM01 and Lut pretreatment. (F) The results of SERCA2a activity in vivo. Data are presented as mean \pm SEM $(n=3)$. aa $\mathrm{P}<0.01$, aaa $\mathrm{P}<0.001$ versus Sham; bb $\mathrm{P}<0.01$, bbb $\mathrm{P}<0.001$ versus $\mathrm{I} / \mathrm{R}$; c $\mathrm{P}<0.05$, ccc $\mathrm{P}<0.001$ versus Lut+I/R; d $\mathrm{P}<0.05$, ddd $\mathrm{P}<0.001$ versus $\mathrm{AV}$-sh-SUM01+I/R; $\Delta \Delta \Delta \mathrm{P}<0.001$ versus Con; ${ }^{*} \mathrm{P}<0.05,{ }^{*} \mathrm{P}<0.01,{ }^{*} * * \mathrm{P}<0.001$ versus $\mathrm{SI} / \mathrm{R}$; $\# \mathrm{P}<0.05$, \#\#P<0.01, \#\#\#P<0.001 versus $\mathrm{Lut}+\mathrm{SI} / \mathrm{R}$; $\& \& \mathrm{P}<0.01, \& \& \& \mathrm{P}<0.001$ versus si-SUM01+SI $/ \mathrm{R}$; $\% \mathrm{P}<0.05, \quad \% \% \% \mathrm{P}<0.001$ versus si-con+SI/R; @@@P $<0.001 \quad$ versus si-SUM01+Lut+SI/R; $\$ \mathrm{P}<0.05, \$ \$ \$ \mathrm{P}<0.001$ versus EGFP-SUM01+SI/R; $\wedge \wedge \wedge \mathrm{P}<0.001$ versus EGFP-con+SI/R; $\star \mathrm{P}<0.05$ versus EGFP-SUM01+Lut+SI/R.

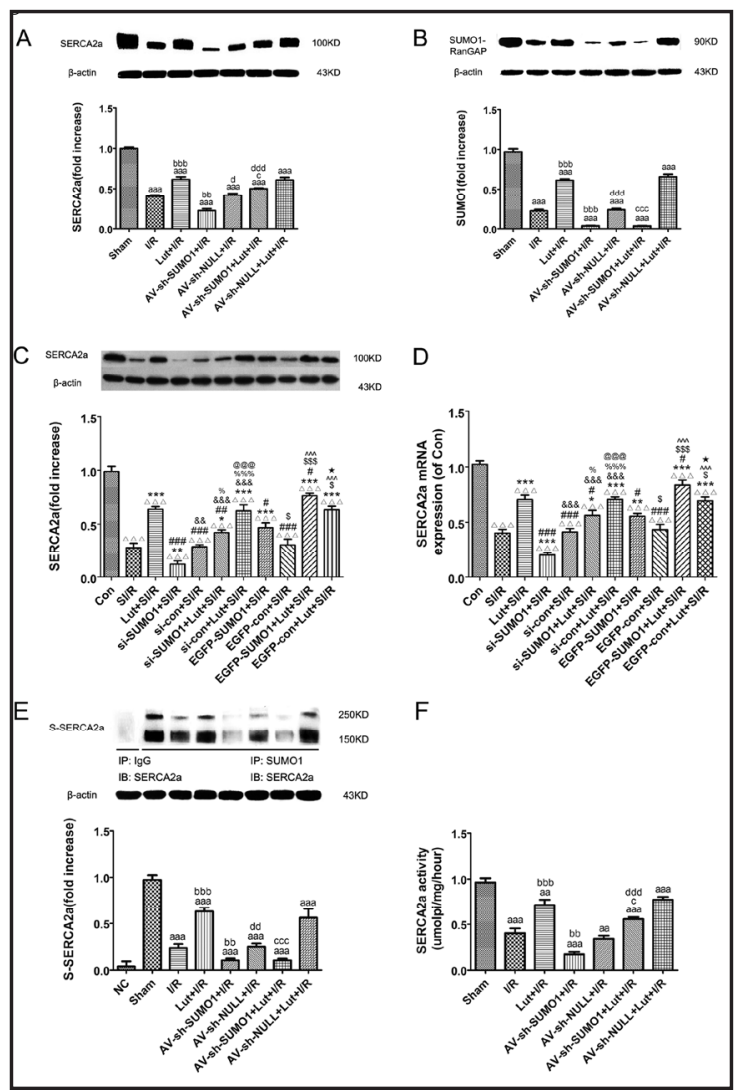

\section{Results}

Lut reversed the reduction of SERCA2a, SUMO1 protein expression and increased the SUMOylation and stability of SERCA2 a after SI/R injury

SERCA2a and SUM01 protein expression was detected by western blot and theSUMOylation and stability of SERCA2a were determined in vitro. During SI/R, the protein levels of SERCA2a and SUM01 decreased compared to the Con group (both $\mathrm{P}<0.001$ ). Pretreatment with Lut partly reversed the reduction in SERCA2a and SUM01 protein expression in the SI/R group (both $\mathrm{P}<0.001$ ) (Fig. 1A-B).

A SUMOylation assay was used to determine the level of SUMOylated SERCA2a (S-SERCA2a). A significant reduction in the level of S-SERCA2a was observed following SI/R $(\mathrm{P}<0.001)$. However, following pretreatment with Lut, the expression of S-SERCA2a was partly restored $(\mathrm{P}<0.05)$ (Fig. 1C).

To assess whether Lut influenced SERCA2a stability, we first compared the half-life of SERCA2a by performing cycloheximide time-course experiments upon transfection into HL-1 cells. SERCA2a in the SI/R group was less stable $(\mathrm{t} 1 / 2=2.1 \mathrm{~d})$ than in the Con group where the half-life was estimated to be approximately $4.9 \mathrm{~d}$. Lut pretreatment increased SERCA2a stability which was reduced by SI/R injury (Fig. 1D).

\section{The optimal concentration of Lut in vivo}

Compared with the Sham group, the LDH level was significantly increased and MTT level was decreased following I/R injury. Both LDH and MTT level were not significantly different in the I/R group and I/R+DMSO group. Pretreatment with Lut $15 \mu \mathrm{g} / \mathrm{kg}$ and 20 $\mu \mathrm{g} / \mathrm{kg}$ decreased LDH level and increased MTT level significantly when compared to the I/R group. Therefore, Lut $15 \mu \mathrm{g} / \mathrm{kg}$ was used in the follow-up experiment (Fig. 1E-F). 


\section{Cellular Physiology Cell Physiol Biochem 2018;45:883-898

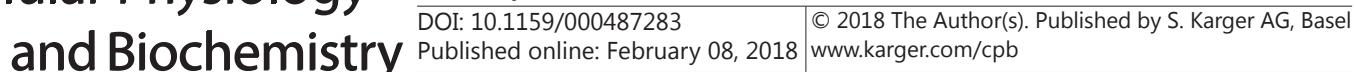

\section{Lut increased SERCA2 a protein expression partly through SUMO1}

The filtration and efficiency of AV-sh-SUMO1, si-SUMO1 and EGFP-SUMO1 were shown in Fig. 2. Myocardial green fluorescence and SUMO1 protein level were significantly decreased in AV-sh-SUM01-injected hearts compared with AV-sh-NULL-injected animals (Fig. 2A-B). Transfection with si-SUMO1 resulted in significantly decrease in the expressions of SUMO1 protein and mRNA (Fig. 2C-D). The protein and mRNA levels of SUMO1 were increased after EGFP-SUM01 transfecton in cells (Fig. 2E-F). As shown in Fig. 3, SUMO1 was knocked down and over-expressed to determine the relationship between SERCA2a and SUMO1 in vivo and in vitro. In vitro, SERCA2a and SUMO1 protein level declined following I/R injury $(\mathrm{P}<0.001)$, and this decrease was partly reversed by pretreatment with Lut $(\mathrm{P}<0.001)$ (Fig. $3 \mathrm{~A}-\mathrm{B}$ ). Compared with the si-Con+SI/R group, the protein expression of SERCA2a was decreased in the si-SUM01+SI/R group $(\mathrm{P}<0.01)$ (Fig. 3C). SERCA2a protein level in the siSUM01+Lut+SI/R group was increased compared to the si-SUM01+SI/R group $(\mathrm{P}<0.001)$, but was decreased when compared to the Lut+SI/R group $(\mathrm{P}<0.05)$ (Fig. $3 \mathrm{C})$. The level of SERCA2a protein following treatment with AV-sh-SUM01 in vivo was consistent with the above results (Fig. 3A). The over-expression of SUMO1 up-regulated SERCA2a protein level during I/R injury $(\mathrm{P}<0.001)$, which was more effective with simultaneous Lut pretreatment $(\mathrm{P}<0.001)$ (Fig. 3C). The level of SERCA2a mRNA and SERCA2a protein showed the same trend (Fig. 3D).

\section{Lut enhanced SUMOylation of SERCA2a and SERCA2 a activity in vivo}

I/R injury decreased the expression of S-SERCA2a. Pretreatment with Lut significantly increased S-SERCA2a expression. Compared with the Lut+I/R group, S-SERCA2a level decreased in the AV-sh-SUM01+Lut+I/R group (Fig. 3E). SERCA2a activity showed the same trend with S-SERCA2a expression (Fig. 3F).

\section{Lut decreased myocardial infarct size and plasma LDH level partly through SUMO1}

No difference was found in the AAR among the groups (Fig. 4A-B). A significant increase in both infarct size and LDH level was observed following I/R injury compared to the Sham group. Pretreatment with Lut reduced infarct size and LDH level due to I/R injury. Infarct size and LDH levels in the AV-sh-SUM01+Lut+I/R group were higher than those in the Lut+I/R group, but lower than those in the AV-sh-SUM01+I/R group (Fig. 4C-D).

Fig. 4. Detection of myocardial infarction area and serum LDH level. (A) Evans blue staining of each group. Blue-stained is the non-ischemic myocardium. Blue-unstained is the danger area. White is the infarct area. The yellow lines are the ischemic boundary. (B) The results of AAR. Risk area is expressed as the percentage of Evans blue-unstained area to the whole left ventricle area. (C) Infarct size is expressed as the percentage of TTC-unstained area to Evans blue-unstained area. (D) Level of serum LDH in each group. Data are presented as mean \pm SEM $(n=3)$. aa $\mathrm{P}<0.01$, aaa $\mathrm{P}<0.001$ versus Sham; bb $\mathrm{P}<0.01$, bbb $\mathrm{P}<0.001$ versus $\mathrm{I} / \mathrm{R}$; ccc $\mathrm{P}<0.001$ versus Lut $+\mathrm{I} / \mathrm{R}$; ddd $\mathrm{P}<0.001$ versus AV-sh-SUM01+I/R.

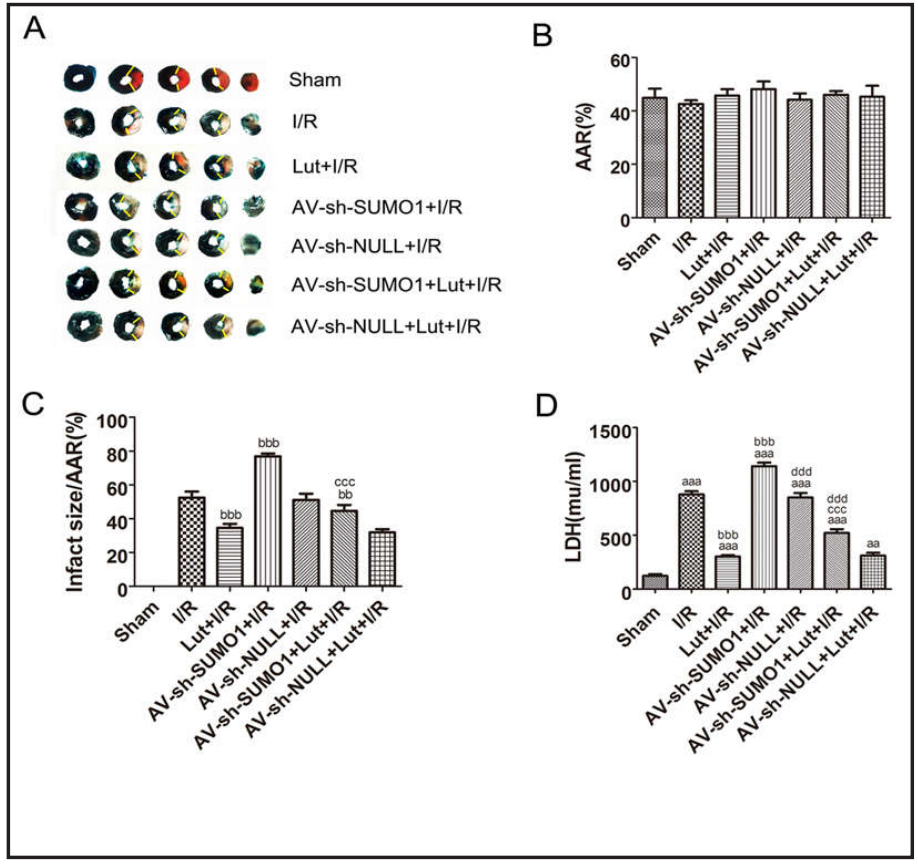


Fig. 5. Changes of cardiac function in each group. (A-E) The results of LVSP, LVEDP, +dp/dtmax, -dp/ dtmax and HR respectively. Data are presented as mean \pm SEM $(n=3)$. aaa $\mathrm{P}<0.001$ versus Sham; b $\mathrm{P}<0.05$, bbb $\mathrm{P}<0.001$ versus $I / R ; c \quad P<0.05$, cc $\mathrm{P}<0.01$, ccc $\mathrm{P}<0.001$ versus Lut $+\mathrm{I} / \mathrm{R}$; dd $\mathrm{P}<0.01$, ddd $\mathrm{P}<0.001$ versus AV-shSUM01+ I/R.

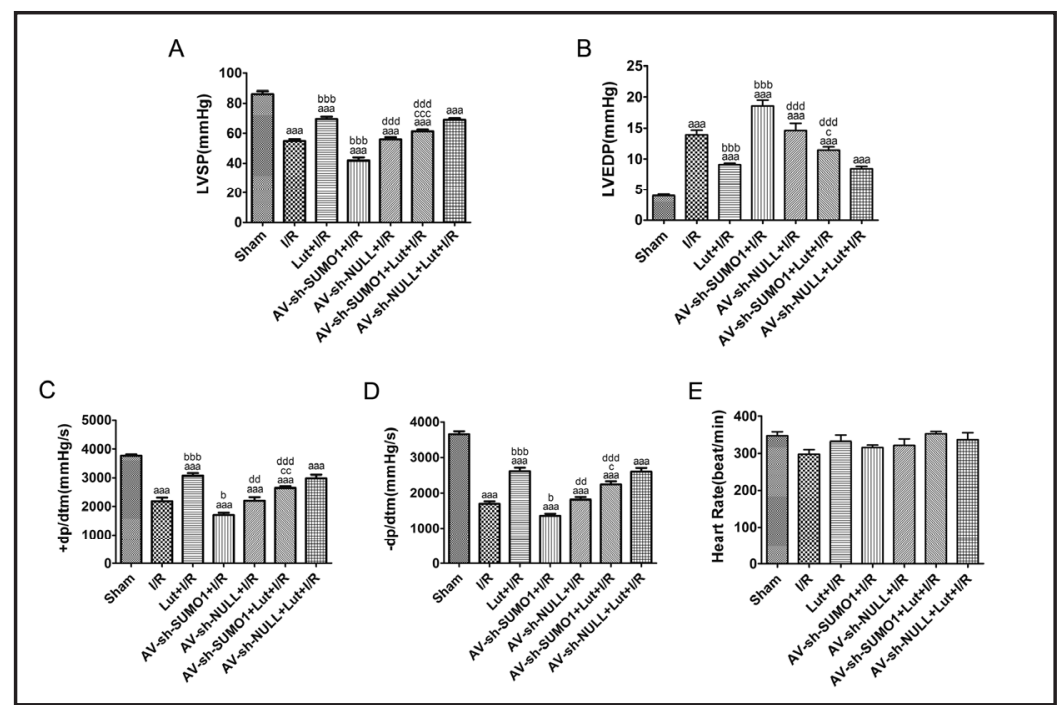

Fig. 6. Lut downregulates cardiomyocyte apoptosis and improves mitochondrial membranepotential $(\triangle \Psi \mathrm{m})$ partly through SUMO1. (A) The protein expressions of Bcl-2 and Bax. (B) The level of CCaspase-3 protein. (C) The ratio of $\mathrm{Bcl}-2 / \mathrm{Bax}$ in each group. (D) HL-1 cells were pre-treated with siRNA to knockdown SUMO1 and plasmids to over-express SUMO1. Cells stimulated with SI/R following the pretreatment of Lut were stained with Annexin V APC/PI before apoptosis was analyzed by flow cytometry. (E) Analysis of mitochondrial membranepotential $(\Delta \Psi \mathrm{m})$ in each treatment group. Data are presented as mean \pm SEM $(\mathrm{n}=3)$. aa $\mathrm{P}<0.01$, aaa $\mathrm{P}<0.001$ versus Sham; bb $\mathrm{P}<0.01$, bbb $\mathrm{P}<0.001$ versus $I / R ; c \quad P<0.05$, cc $\mathrm{P}<0.01$. ccc $\mathrm{P}<0.001$ versus Lut+I/R; dd $\mathrm{P}<0.01$, ddd $\mathrm{P}<0.001$ versus $\mathrm{AV}$-shSUM01+I/R; $\Delta \Delta \Delta \mathrm{P}<0.001$ versus Con; ${ }^{*} \mathrm{P}<0.05,{ }^{* *} \mathrm{P}<0.01 .{ }^{* * *} \mathrm{P}<0.001$ versus $\mathrm{SI} / \mathrm{R}$; $\# \mathrm{P}<0.05, \# \# \mathrm{P}<0.01$, $\# \# \# \mathrm{P}<0.001$ versus Lut+SI/R; $\& \& \mathrm{P}<0.01, \& \& \& \mathrm{P}<0.001$ versus siSUM01+SI $/ \mathrm{R} ; \% \mathrm{P}<0.05, \% \% \mathrm{P}<0.01$, $\% \% \% \mathrm{P}<0.001$ versus si-con+SI/R; @@P $<0.01$, @@@P $<0.001$ versus si-SUM01+Lut+SI/R; $\quad \$ \$ P<0.01$, $\$ \$$ P $<0.001$ versus EGFPSUM01+SI/R; $\wedge^{\wedge \wedge} \mathrm{P}<0.001$ versus


EGFP-con+SI/R; $\star \mathrm{P}<0.05$ versus EGFP-SUM01+Lut+SI/R.

\section{KARGER}


Regulated SUMO1 expression changed the effect of Lut on cardiac function

$\mathrm{I} / \mathrm{R}$ injury resulted in a significant decrease in heart function. A significant increase in LVEDP was found, as well as a reduction in LVSP, $+\mathrm{dP} / \mathrm{dtmax}$ and $-\mathrm{dP} / \mathrm{dtmax}$. Pretreatment with Lut significantly improved damaged cardiac function caused by I/R injury. Following knockdown of SUM01, cardiac function which was improved by Lut was significantly weakened compared with the Lut+I/R group. Compared with the I/R+AV-sh-SUMO1 group, heart function was improved in the AV-sh-SUM01+Lut+I/R group (Fig. 5).

Up-regulation of SUMO1 by Lut inhibited apoptosis proteins expression in vivo

To investigate apoptosis in each group, the expression of Vcl-2, Bax, Caspase-3 and Cleaved-Caspase-3 (C-Caspase-3) were measured in vivo. I/R promoted apoptosis as it enhanced the expression of pro-apoptotic proteins, Baxand C-Caspase-3, and reduced the antiapoptotic protein level of Bcl-2 and Caspase-3. Pretreatment with Lut significantly increased anti-apoptotic protein levels and decreased the expression of pro-apoptotic proteins. When compared with the Lut+I/R group, anti-apoptotic proteins in the AV-sh-sumo1+Lut+I/R group were significantly reduced and pro-apoptotic proteins were significantly upregulated. The ratio of Bcl-2 and Bax expression is known to be a determining factor in resistance to apoptosis. We found that this ratio was significantly decreased following myocardial I/R injury, but was enhanced by Lut pretreatment (Fig. 6A-C).

Lut regulates SUMO1 to decline $\triangle \Psi m$ in $H L-1$ cells

The ratio of JC-1 monomer/aggregate emission is dependent only on the $\Delta \Psi \mathrm{m}$ and no other factors. An increase in this ratio reflects low $\Delta \Psi \mathrm{m}$. The exposure of HL-1 cardiomyocytes to SI/R injury resulted in a decline in $\Delta \Psi \mathrm{m}(\mathrm{P}<0.001)$, which partly recovered following Lut pretreatment $(\mathrm{P}<0.001)$. Si-SUM01 significantly aggravated the damage to $\Delta \Psi \mathrm{m}$ caused by SI/R injury $(\mathrm{P}<0.001)$, which was partly relieved by Lut pretreatment $(\mathrm{P}<0.001)$. Moreover, the SI/R-induced decline in $\Delta \Psi \mathrm{m}$ was significantly reduced by transfection with EGFPSUM01 $(\mathrm{P}<0.01)$, and the $\Delta \Psi \mathrm{m}$ was further increased when cells was treated with Lut and EGFP-SUM01 together $(\mathrm{P}<0.001)$ (Fig. 6D).

Influence of Lut on SUMO1 decreased the apoptosis of HL-1 cells

$\mathrm{AV} / \mathrm{PI}$ dual staining showed an increase in the rate of apoptosis in HL-1 cells induced by $\mathrm{SI} / \mathrm{R}$ injury $(\mathrm{P}<0.001)$. Lut pretreatment was found to partly decrease apoptosis $(\mathrm{P}<0.001)$. Transfection with si-SUM01 accelerated the apoptosis of HL-1 cells following SI/R injury $(\mathrm{P}<0.001)$. There were fewer apoptotic cells in the si-SUM01+Lut+SI/R group than in the si-SUM01+SI/R group $(\mathrm{P}<0.001)$. Furthermore, transfection with EGFP-SUM01 reduced the

Fig. 7. SUMO1 is conjugated to lysines 585, 480 and 571 of mouse SERCA2a and is required for SERCA2a stability. (A) The evaluation of SERCA2a SUMOylation by Co-IP following transfecting with site mutant plasmids (WT, K585R, K480R, K571R, K585R/K480R, K585R/ K571R, and K585R/K480R/571R). (B) Effects of SUM01 over-expression on the stability of WT and K585R/K480R/571R SERCA2a

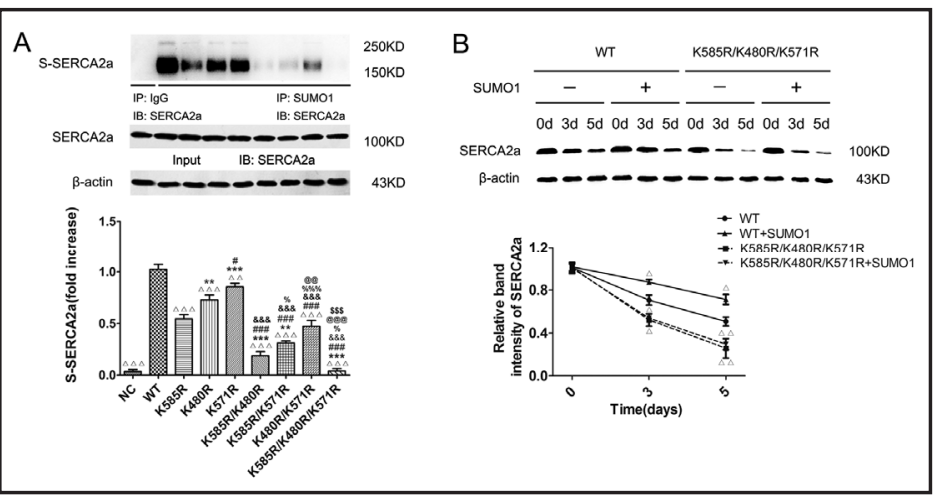
mutant protein in HL-1 cells. Data are presented as mean $\pm \mathrm{SEM}(\mathrm{n}=3) . \Delta \Delta \mathrm{P}<0.01, \Delta \Delta \Delta \mathrm{P}<0.001$ versus $\mathrm{WT} ;{ }^{* *} \mathrm{P}<0.01,{ }^{* * *} \mathrm{P}<0.001$ versus $\mathrm{K} 585 \mathrm{R}$; \#P<0.05, \#\#\# $<0.001$ versus $\mathrm{K} 480 \mathrm{R} ;$ \&\&\&P<0.001 versus $\mathrm{K} 571 \mathrm{R} ; \% \mathrm{P}<0.05, \% \% \% \mathrm{P}<0.001$ versus K585R/K480R; @@@P<0.001 versus K585R/K571R; \$\$P<0.001 versus K480RK/571R. 
percentage of apoptotic cells induced by SI/R $(\mathrm{P}<0.001)$, which was further reduced by pretreatment with Lut following transfection with EGFP-SUM01 ( $<<0.001)$ (Fig. 6E).

\section{Three SUMO conjugation sites in mouse SERCA2a}

Three potential SUMOylation sites K585, K480 and K571 of mouse SERCA2a were predicted by the SUMOplot ${ }^{\mathrm{TM}}$ Analysis Program (http://www.abgent.com/sumoplot). These SUMO conjugation sites were evaluated by co-immunoprecipitation following transfection with several site mutant plasmids. The single-lysine mutation of K585R, K480R and K571R decreased SERCA2a SUMOylation compared with the WT group, in which the effect of K585R was the most obvious. SERCA2a SUMOylation was further reduced with the transfection of double-lysine mutant plasmids. In addition, the triple-lysine mutant, K585R/K480R/K571R, was completely un-SUMOylated (Fig. 7A).

\section{SUMO1 increases SERCA2a stability}

When SUMO1 was co-expressed, the estimated half-life of SERCA2a protein increased compared to the WT. The estimated half-life of the K585R/K480R/K571R mutant was significantly reduced compared with the WT, which could not been reversed by SUMO1 coexpression (Fig. 7B).

Fig. 8. Lut restores SERCA2a protein stability reduced in SI/R process through SUMOylation at lysine 585. (A) The effects of Lut on SERCA2a stability subject to SI/R injury following transfection with WT. (B) Changes of SERCA2a stability in SI/R process with pretreatment of Lut and transfection with K585R/K480R/571R. K585R abrogates the effect of Lut on SERCA2a stability. (D) Effects of Lut on the stability of K480R SERCA2a mutant protein. (E) The stability of K571R SERCA2a mutant protein in HL-1 cells pretreated with Lut. (F) K585R/K480R ablishes the effect of Lut on SERCA2a stability. (G) Changes of SERCA2a stability in SI/R process with pretreatment of Lut and transfection with K585R/K571R. (D) Effects of Lut on the stability of K480R/ K571R SERCA2a mutant protein. Data are presented as mean \pm SEM $(\mathrm{n}=3) .{ }^{*} \mathrm{P}<0.05$, ${ }^{* *} \mathrm{P}<0.01,{ }^{* * *} \mathrm{P}<0.001$ versus the respective Con; $\# \mathrm{P}<0.05$ versus the respective SI/R.

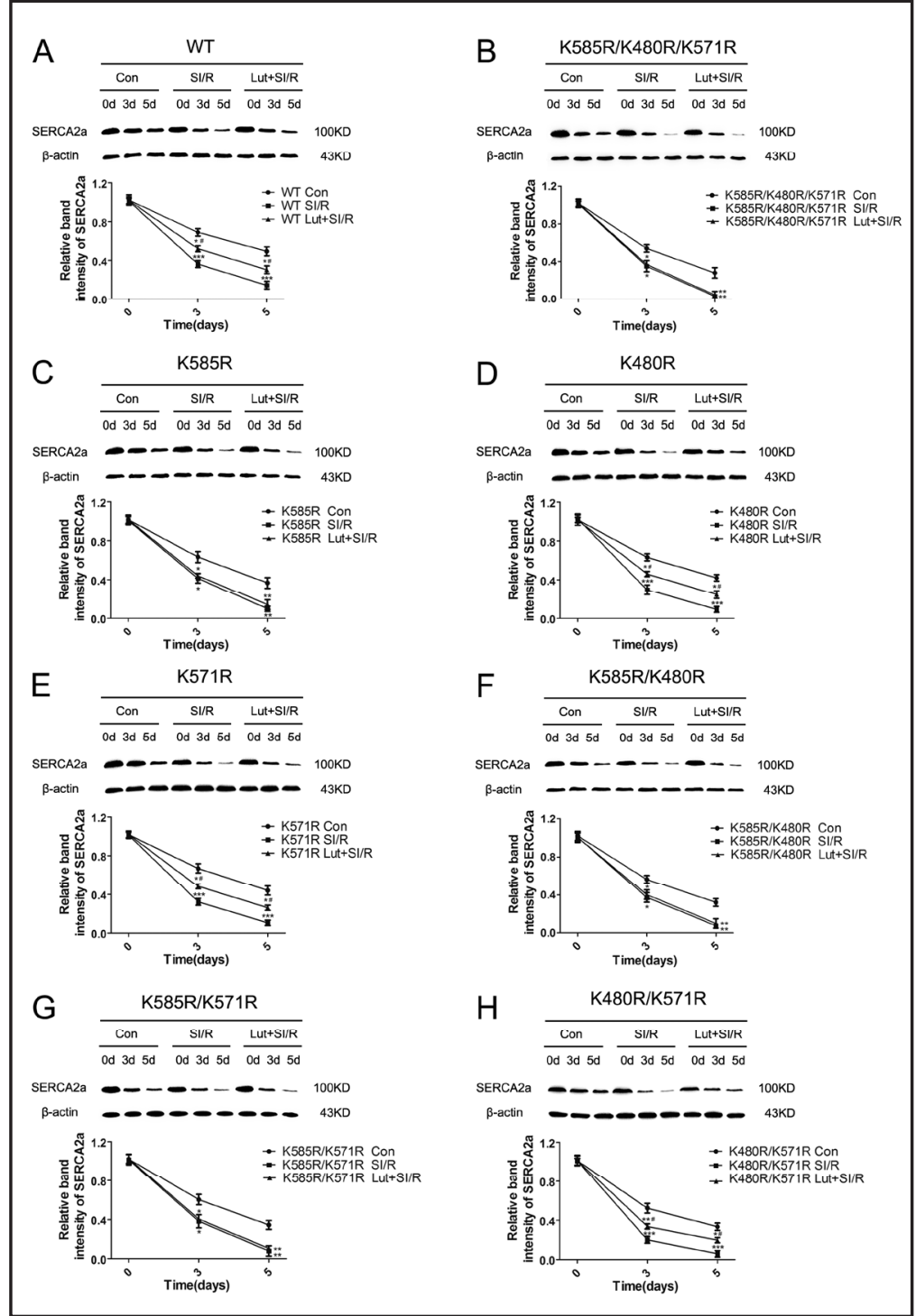




\section{Cellular Physiology Cell Physiol Biochem 2018;45:883-898 and Biochemistry \begin{tabular}{c|c|c|} 
DOI: $10.1159 / 000487283$ \\
Published online: February 08, 2018 & $\begin{array}{l}\text { O } 2018 \text { The Author(s). Published by S. Karger AG, Basel } \\
\text { wwrger.com/cpb }\end{array}$
\end{tabular} \\ Du et al.: Lut Attenuates Myocardial I/R Injury via SERCA2a}

\section{Lut stabilizes SERCA2a mainly through K585}

Lut increased SERCA2a stability which was reduced by SI/R injury following transfection with the WT (Fig. 8A). However, the K585R/K480R/K571R mutant abolished this effect (Fig. 8B), which indicated that Lut influenced SERCA2a stability by regulating SERCA2a SUMOylation. To study the potential SUMOylation acceptor site(s) Lut acted on, we then determined SERCA2a stability following transfection with other site mutant plasmids. One of these, K585, was critical for SERCA2a SUMOylation. K585R abrogated the effect of Lut on SERCA2a stability similar to K585R/K480R, K585R/K571R and K585R/K480R/K571R (Fig. 8B, C, F, G). However, the effect of Lut was not abolished by K480R, K571R or K480R/K571R (Fig. 8D, E, H).

\section{Discussion}

SERCA2a is crucial for maintaining myocardial calcium handling and the systolic/ diastolic function of the heart [28]. Heart dysfunction can be caused in the inducible cardiacspecific SERCA2a knockdown mouse [29, 30]. It has been discovered that the expression of SERCA2a was decreased in I/R cardiomyocytes [31]. Our study provided similar evidence that SERCA2a expression declined following I/R injury, but Lut partly restored the level of SERCA2a. Moreover, Lut protected cardiomyocytes against I/R injury, including decreasing apoptosis and improving $\Delta \Psi \mathrm{m}$. It has been reported that with the decline of SERCA2a level, myocardial cells lose their ability to transport calcium from the cytosol into the SR. The abnormal high cytoplasmic calcium level could result in mitochondrial permeability transition pore opening, $\Delta \Psi \mathrm{m}$ decrease, and finally cause apoptosis of cardiomyocytes [32]. In addition, Lut can regulate cell apoptosis by enhancing autophagy [33, 34]. These may be the mechanism involved in the protective effect of Lut on I/R cardiomyocytes.

SUM01 is one of three SUMO isoforms found in the myocardium [35]. SUMO1 usually modifies its substrate as a monomer, whereas SUMO2 and SUMO3 can build up poly-SUMO chains as they are closely related and are usually described as SUMO2/3 [36]. Notably, only SUM01 binds to two lysine residues of SERCA2a and modulates the level and activity of SERCA2a in cardiomyocytes [37]. In the present study, it was confirmed that Lut restored SUM01 expression reduced by myocardial I/R injury. Moreover, over-expression of SUMO1 increased SERCA2a mRNA and protein expression, improved $\triangle \Psi \mathrm{m}$ and reduced the number of apoptotic cells. As a regulator of SERCA2a, SUMO1 can enhance the function of SERCA2a, but its role was less obvious than the corresponding effect of Lut. Lut may have a protective effect on myocardial cells through other mechanisms. In addition, when SUM01 was knocked down, the expression and activity of SERCA2a as well as SERCA2a SUMOylation were decreased, and myocardial I/R injury was then aggravated which increased infarction areas, reduced cardiac function, lowered $\Delta \Psi \mathrm{m}$ and increased apoptosis, which suggested that SUMO1 has protective effects in myocardial I/R injury. However, the above injury was partly restored by pretreatment with Lut. This recovery may be due to other mechanisms related to the cardioprotective effects of Lut. It is suggested that Lut up-regulated SERCA2a not entirely, but partially via SUMO1.

SERCA2a has been reported to be modified at multiple levels of a signaling cascade consisting of phospholamban, protein phosphatase 1 , inhibitor-1, and protein kinase $\mathrm{C} \alpha(\mathrm{PKC} \alpha)$ [38]. Our previous study has demonstrated that Lut can improve myocardial contractile function in I/R injury through the ERK/PP1a/PLB/SERCA2a signaling pathway [20], and enhancing SERCA2a activity by p38 MAPK Signaling [39]. In terms of transcription factors, a number of studies have provided compelling evidence that HIF- $1 \alpha$, SP1 and Egr-1 are involved in the regulation of SERCA2a [40-42]. In addition to SUMOylation, SERCA2a may have a cardioprotective effect due to other protein modifications, such as nitration [43], carbonylation [44], and glutathione-based [45]. Moreover, an important mechanism of SUMOylation is competing with other modifications of the target at the acceptor lysine residue. Potential alternative modifications are acetylation, ubiquitylation and methylation 
[46]. It has been reported that SUMO modification can compete with other modifications of SERCA2a, especially acetylation [47]. Whether Lut regulates SERCA2a through the above mechanisms requires further investigation.

The SUMOylation pathway plays a prominent role in diverse cellular processes, involving altered localization, activity and stability of the target protein 46 . Our previous study has reported that Lut could improve activity and Sumoylation of SERCA2a in cardiomyocytes of heart failure rats [48]. In our present study, we further investigated the effect of Lut on SERCA2a SUMOylation in I/R injury. We found that decreased SERCA2a SUMOylation induced by I/R injury was restored by Lut pretreatment. Furthermore, we proved the above effect of Lut by knocking down SUM01 in vivo. Additionally, its mechanism was explored in terms of SUMO conjugation sites in SERCA2a. It has been reported that two putative SUMO conjugation sites on human SERCA2a, lysine 585 and 480, are conserved in mouse and human SERCA2a [37]. Nevertheless, we observed lysine 585, 480 and 571 to be SUMO acceptor sites in mouse SERCA2a. Of these, lysine 571 has never been reported, and lysine 585 and 480 were consistent with a previous study. Moreover, we found that Lut improved SERCA2a stability which declined following I/R. However, the K585R mutant abolished this ability of Lut, similar to K585R/K480R/K571R. It is concluded that Lut enhanced SERCA2a stability by regulating SERCA2a SUMOylation mainly at lysine 585. It is known that protein stability is one of the main factors mediating protein expression. The increased protein expression of SERCA2a by Lut may be caused by the above mechanisms. SUMOylation may induce a conformational change [49] in SERCA2a. It is possible that SUMOylation provides an additional interface for ATP binding, leading to increased ATPase activity. It has been reported the control of protein expression through mRNA stability in calcium signalling [50]. Zhang et al. observed that SUMOylation of Nucleolin at K294 mediated cell death by regulating gadd 45 mRNA stability [51]. 3-UTR mRNA pull-down assays and Western blot analysis indicated that the AU binding protein AUF1 interacted with the SERCA2a 3-UTR, which affected mRNA stability [52]. Further elucidation needs be explored that whether the effect of Lut on SUMOylation of SERCA2a at K585 has any relationship with mRNA stability. The action site of Lut on lysine 585 might provide a potential therapeutic target for the clinical prevention and treatment of myocardial I/R injury.

The SUMOylation and ubiquitination processes share similarities in terms of the threedimensional structures of SUMO and ubiquitin proteins. SUMOylation prevents the substrate from depredating by the ubiquitin-proteasome system. In addition, as a reversible and dynamic process, SUMOylation is reversed by a family of Sentrin-specific proteases (SENPs). SENP1 can protect against myocardial I/R injury [53]. Further experiments are required to determine whether Lut increases SERCA2a stability by reducing its ubiquitination, and whether SENP1 is involved in the mechanism by which Lut attenuates myocardial I/R injury.

There are several vital findings in the present study. First, Lut upregulates SERCA2a partly through SUMOylation to attenuate myocardial I/R injury. Second, Lut increases the protein stability of SERCA2a by improving its SUMOylation, which contributes to the upregulation of SERCA2a. Third, the putative SUMO conjugation sites in mouse SERCA2a include lysine 585, 480 and 571 of these, lysine 585 is the main SUMO acceptor site by which Lut affects SERCA2a stability. These findings may represent a novel strategy by which Lut protects the heart from I/R injury and this strategy requires further investigation.

\section{Acknowledgements}

We thank Dr. William Claycomb (Louisiana State University Health Science Center, New Orleans, LA, USA) for kindly providing for HL-1 cells. This work is supported by National Natural Science Foundation of China (Grant: 81341009). The authors thank Yuanyuan Luo and $\mathrm{Ya} \mathrm{Hu}$ for revision assistance. 


\section{Cellular Physiology Cell Physiol Biochem 2018;45:883-898 \begin{tabular}{ll|l} 
and Biochemistry & Published online: February 08, 2018 & $\begin{array}{l}\text { (c) } 2018 \text { The Author(s). Published by S. Karger AG, Basel } \\
\text { www.karger.com/cpb }\end{array}$ \\
\hline
\end{tabular} \\ Du et al.: Lut Attenuates Myocardial I/R Injury via SERCA2a}

\section{Disclosure Statement}

The authors declare that they have no competing interests.

\section{References}

1 Minamino T: Cardioprotection from ischemia/reperfusion injury: basic and translational research. Circ J 2012;76:1074-1082.

-2 Sluijter JP, Condorelli G, Davidson SM, Engel FB, Ferdinandy P, Hausenloy DJ, Lecour S, Madonna R, Ovize M, Ruiz-Meana M, Schulz R, Van Laake LW; Nucleus of the European Society of Cardiology Working Group Cellular Biology of the Heart: Novel therapeutic strategies for cardioprotection. Pharmacol Ther 2014;144:60-70.

-3 Cabrera-Fuentes HA, Alba-Alba C, Aragones J, Bernhagen J, Boisvert WA, Bøtker HE, Cesarman-Maus G, Fleming I, Garcia-Dorado D, Lecour S, Liehn E, Marber MS, Marina N, Mayr M, Perez-Mendez O, Miura T, Ruiz-Meana M, Salinas-Estefanon EM, Ong SB, Schnittler HJ, Sanchez-Vega JT, Sumoza-Toledo A, Vogel CW, Yarullina D, Yellon DM, Preissner KT, Hausenloy DJ: Meeting report from the 2nd International Symposium on New Frontiers in Cardiovascular Research. Protecting the cardiovascular system from ischemia: between bench and bedside. Basic Res Cardiol 2016;111:7.

4 Talukder MA, Zweier JL, Periasamy M: Targeting calcium transport in ischaemic heart disease. Cardiovasc Res 2009;84:345-352.

5 Fauconnier J, Roberge S, Saint N, Lacampagne A: Type 2 ryanodine receptor: a novel therapeutic target in myocardial ischemia/reperfusion. Pharmacol Ther 2013;138:323-332.

-6 Kranias EG, Hajjar RJ: Modulation of cardiac contractility by the phospholamban/SERCA2a regulatome. Circ Res 2012;110:1646-1660.

7 Zhang N, Zhu B: The role of the rat sarcoplasmic reticulum Ca2+-ATPase promoter in myocardial ischemiapreconditioning. Mol Cell Biochem 2010;333:311-321.

$>8$ Zhang CM, Gao L, Zheng YJ, Yang HT: Berbamine protects the heart from ischemia/reperfusion injury by maintaining cytosolic Ca ${ }^{2+}$ homeostasis and preventing calpain activation. Circ J 2012;76:1993-2002.

-9 Yeung HM, Hung MW, Lau CF, Fung ML: Cardioprotective effects of melatonin against myocardial injuries induced by chronic intermittent hypoxia in rats. J Pineal Res 2015;58:12-25.

10 Wang J, Schwartz RJ: Sumoylation and regulation of cardiac gene expression. Circ Res 2010;107:19-29.

11 Mendler L, Braun T, Müller S:The Ubiquitin-Like SUMO System and Heart Function: From Development to Disease. Circ Res 2016;118:132-144.

12 Gareau JR, Lima CD: The SUMO pathway: emerging mechanisms that shape specificity, conjugation and recognition. Nat Rev Mol Cell Biol 2010;11:861-871.

13 Kim EY, Zhang Y, Beketaev I, Segura AM, Yu W, Xi Y, Chang J, Wang J: SENP5, a SUMO isopeptidase, induces apoptosis and cardiomyopathy. J Mol Cell Cardiol 2015;78:154-164.

14 Shimizu Y, Lambert JP, Nicholson CK, Kim JJ, Wolfson DW, Cho HC, Husain A, Naqvi N, Chin LS, Li L, Calvert JW: DJ-1 protects the heart against ischemia-reperfusion injury by regulating mitochondrial fission. J Mol Cell Cardiol 2016;97:56-66.

-15 Tilemann L, Lee A, Ishikawa K, Aguero J, Rapti K, Santos-Gallego C, Kohlbrenner E, Fish KM, Kho C, Hajjar RJ: SUM0-1 gene transfer improves cardiac function in a large-animal model of heart failure. Sci Transl Med 2013;5:211ra159.

16 Kho C, Lee A, Jeong D, Oh JG, Gorski PA, Fish K, Sanchez R, DeVita RJ, Christensen G, Dahl R, Hajjar RJ: Smallmolecule activation of SERCA2a SUMOylation for the treatment of heart failure. Nat Commun 2015;6:7229.

17 Bian C, Xu T, Zhu H, Pan D, Liu Y, Luo Y, Wu P, Li D: Luteolin Inhibits Ischemia/Reperfusion-Induced Myocardial Injury in Rats via Downregulation of microRNA-208b-3p. PLoS One 2015;10:e0144877.

18 Fang F, Li DY, Pan HJ, Chen D, Qi LL, Zhang RQ, Sun H: Luteolin inhibits apoptosis and improves cardiomyocyte contractile function through the PI3K/Akt pathway in simulated ischemia/reperfusion. Pharmacology 2011;88:149-158.

19 Nai C, Xuan H, Zhang Y, Shen M, Xu T, Pan D, Zhang C, Zhang Y, Li D: Luteolin Exerts Cardioprotective Effects through Improving Sarcoplasmic Reticulum $\mathrm{Ca}(2+)$-ATPase Activity in Rats during Ischemia/Reperfusion In vivo. Evid Based Complement Alternat Med 2015;2015:365854. 


\section{Cellular Physiology Cell Physiol Biochem 2018;45:883-898 and Biochemistry DOI: 10.1159/000487283 2018 Published 2018 The Author(s). Published by S. Karger AG, Basel \\ Du et al.: Lut Attenuates Myocardial I/R Injury via SERCA2a}

20 Wu X, Xu T, Li D, Zhu S, Chen Q Hu W, Pan D, Zhu H, Sun H: ERK/PP1a/PLB/SERCA2a and JNK pathways are involved in luteolin-mediated protection of rat hearts and cardiomyocytes following ischemia/reperfusion. Plos One 2013;8:e82957.

-21 Wu Q, Zhao Z, Sun H, Hao YL, Yan CD, Gu SL: Oestrogen changed cardiomyocyte contraction and $\beta$ adrenoceptor expression in rat hearts subjected to ischaemia-reperfusion. Exp Physiol 2008;93:10341043.

22 Claycomb WC, Lanson NA Jr, Stallworth BS, Egeland DB, Delcarpio JB, Bahinski A, Izzo NJ Jr: HL-1 cells: a cardiac muscle cell line that contracts and retains phenotypic characteristics of the adult cardiomyocyte. Proc Natl Acad Sci USA 1998;95:2979-2984.

-23 Beharier O, Dror S, Levy S, Kahn J, Mor M, Etzion S, Gitler D, Katz A, Muslin AJ, Moran A, Etzion Y: ZnT-1 protects HL-1 cells from simulated ischemia-reperfusion through activation of Ras-ERK signaling. J Mol Med (Berl) 2012;90:127-138.

-24 Brady NR, Hamacher-Brady A, Gottlieb RA: Proapoptotic BCL-2 family members and mitochondrial dysfunction during ischemia/reperfusion injury, a study employing cardiac HL-1 cells and GFP biosensors. Biochim Biophys Acta 2006;1757:667-678.

-25 Zheng LR, Han J, Yao L, Sun YL, Jiang DM, Hu SJ, Shao L, Sun ZH, Wang LH: Up-regulation of calcitonin generelated peptide protects streptozotocin-induced diabetic hearts from ischemia/reperfusion injury. Int J Cardiol 2012;156:192-198.

-26 Sun D,Huang J,Zhang Z,Gao H,Li J,Shen M,Cao F,Wang H: Luteolin limits infarct size and improves cardiac function after myocardium ischemia/reperfusion injury in diabetic rats. PLoS One 2012;7:e33491.

27 Zhou Q Zhang L, Chen Z, Zhao P, Ma Y, Yang B, He Q, Ying M. Small ubiquitin-related modifier-1 modification regulates all-trans-retinoic acid-induced differentiation via stabilization of retinoic acid receptor $\alpha$. The FEBS J, 2014, 281:3032-3047.

-28 Boardman NT, Aronsen JM, Louch WE, Sjaastad I, Willoch F, Christensen G, Sejersted O, Aasum E: Impaired left ventricular mechanical and energetic function in mice after cardiomyocyte-specific excision of Serca2 Am J Physiol Heart Circ Physiol 2014;306:H1018-H1024.

29 Louch WE, Hougen K, Mørk HK, Swift F, Aronsen JM, Sjaastad I, Reims HM, Roald B, Andersson KB, Christensen G, Sejersted OM: Sodium accumulation promotes diastolic dysfunction in end-stage heart failure following Serca2 knockout. J Physiol 2010;588:465-478.

-30 Andersson KB, Birkeland JA, Finsen AV, Louch WE, Sjaastad I, Wang Y, Chen J, Molkentin JD, Chien KR, Sejersted OM, Christensen G: Moderate heart dysfunction in mice with inducible cardiomyocyte-specific excision of the Serca2 gene. J Mol Cell Cardiol 2009;47:180-187.

-31 Takeo S, Nasa Y, Tanonaka K, Yamaguchi F, Yabe K, Hayashi H, Dhalla NS: Role of cardiac rennin-angiotensin system in sarcoplasmic reticulum function and gene expression in the ischemic-reperfused heart. Mol Cell Biochem 2000;212:227-235.

32 Li L, Tan H, Gu Z, Liu Z, Geng Y, Liu Y, Tong H, Tang Y, Qiu J, Su L: Heat Stress Induces Apoptosis through a Ca2+-Mediated Mitochondrial Apoptotic Pathway in Human Umbilical Vein Endothelial Cells. PloS one 2014;9:e111083.

-33 Cao Z, Zhang H, Cai X, Fang W, Chai D, Wen Y, Chen H, Chu F, Zhang Y: Luteolin Promotes Cell Apoptosis by Inducing Autophagy in Hepatocellular Carcinoma. Cell Physiol Biochem 2017;19:1803-1812.

-34 Zhang BC, Zhang CW, Wang C, Pan DF, Xu TD, Li DY: Luteolin Attenuates Foam Cell Formation and Apoptosis in Ox-LDL-Stimulated Macrophages by Enhancing Autophagy. Cell Physiol Biochem 2016;39:2065-2076.

-35 Yeh ET: SUMOylation and de-SUMOylation: wrestling with life's processes. J Biol Chem 2009;284:82238227.

-36 Vejpongsa P, Yeh ET: Wrestling with heart failure: SUMO-1 to the rescue. Circ Res 2014;114:1561-1563.

37 Kho C, Lee A, Jeong D, Oh JG, Chaanine AH, Kizana E, Park WJ, Hajjar RJ: SUM01-dependent modulation of SERCA2a in heart failure. Nature 2011;477:601-605.

38 Park WJ, Oh JG: SERCA2a: a prime target for modulation of cardiac contractility during heart failure. BMB Rep 2013;46: 237-243.

-39 Zhu S, Xu T, Luo Y, Zhang Y, Xuan H, Ma Y, Pan D, Li D, Zhu H: Luteolin Enhances Sarcoplasmic Reticulum Ca2+-ATPase Activity through p38 MAPK Signaling thus Improving Rat Cardiac Function after Ischemia/ Reperfusion. Cell Physiol Biochem 2017;41:999-1010. 


\section{Cellular Physiology Cell Physiol Biochem 2018;45:883-898

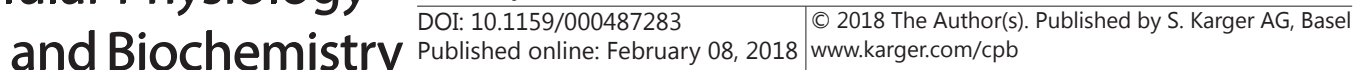

40 Ghosh S, Adhikary A, Chakraborty S, Nandi P, Mohanty S, Chakraborty S, Bhattacharjee P, Mukherjee S, Putatunda S, Chakraborty S, Chakraborty A, Sa G, Das T, Sen PC: Nifetepimine, a Dihydropyrimidone, Ensures CD4+ T Cell Survival in a Tumor Microenvironment by Maneuvering Sarco (endo) plasmic Reticulum Ca2+ ATPase (SERCA). J Biol Chem 2012;287:32881-32896.

41 Bastianelli D, Siciliano C, Puca R, Coccia A, Murdoch C, Bordin A, Mangino G, Pompilio G, Calogero A, De Falco E: Influence of Egr-1 in cardiac tissue-derived mesenchymal stem cells in response to glucose variations. Biomed Res Int 2014;2014:254793.

-42 Ronkainen VP, Skoumal R, Tavi P: Hypoxia and HIF-1 suppress SERCA2a expression in embryonic cardiac myocytes through two interdependent hypoxia response elements. J Mol Cell Cardiol 2011;50:1008-1016.

43 Knyushko TV, Sharov VS, Williams TD, Schöneich C, Bigelow DJ: 3-Nitrotyrosine modification of SERCA2a in the aging heart: a distinct signature of the cellular redox environment. Biochemistry 2005;44:1307113081.

44 Shao CH, Capek HL, Patel KP, Wang M, Tang K, DeSouza C, Nagai R, Mayhan W, Periasamy M, Bidasee KR: Carbonylation contributes to SERCA2a activity loss and diastolic dysfunction in a rat model of type 1 diabetes. Diabetes 2011;60:947-959.

45 Adachi T, Weisbrod RM, Pimentel DR, Ying J, Sharov VS, Schöneich C, Cohen RA: S-Glutathiolation by peroxynitrite activates SERCA during arterial relaxation by nitric oxide. Nat Med 2004;10:1200-1207.

46 Geiss-Friedlander R, Melchior F: Concepts in sumoylation: a decade on. Nat Rev Mol Cell Biol 2007;8:947956.

47 Van Rechem C, Boulay G, Pinte S, Stankovic-Valentin N, Guérardel C, Leprince D: Differential regulation of HIC1 target genes by CtBP and NuRD, via an acetylation/SUMOylation switch, in quiescent versus proliferating cells. Mol Cell Biol 2010;30:4045-4059.

48 Hu W, Xu T, Wu P, Pan D, Chen J, Chen J, Zhang B, Zhu H, Li D: Luteolin improves cardiac dysfunction in heart failure rats by regulating sarcoplasmic reticulum Ca(2+)-ATPase 2a. Sci Rep 2017;7:41017.

49 Baba D, Maita N, Jee JG, Uchimura Y, Saitoh H, Sugasawa K, Hanaoka F, Tochio H, Hiroaki H, Shirakawa M: Crystal structure of thymine DNA glycosylase conjugated to SUMO-1 Nature 2005;435:979-982.

50 Misquitta CM, Chen T: Control of protein expression through mRNA stability in calcium signalling. Cell Calcium 2006;40:329-346.

51 Zhang D, Liang Y, Xie Q, Gao G, Wei J, Huang H, Li J, Gao J, Huang C: A novel post-translational modification of nucleolin, SUMOylation at Lys-294, mediates arsenite-induced cell death by regulating gadd $45 \alpha$ mRNA stability. J Biol Chem 2015;290:4784-4800.

52 Blum JL, Samarel AM: Phosphorylation and binding of AUF1 to the 3'-untranslated region of cardiomyocyte SERCA2a mRNA. Am J Physiol Heart Circ Physiol 2005;289:H2543-H2550.

53 Gu J, Fan Y, Liu X, Zhou L, Cheng J, Cai R, Xue S: SENP1 protects against myocardial ischaemia/reperfusion injury via a HIF1 $\alpha$-dependent pathway. Cardiovasc Res 2014;4:83-92. 